\title{
ESPELHo, FRATURA: NOTAS SOBRe A CRÍTICA DE PHilipPe LeJEUNe
}

Ana Amelia Coelho ${ }^{1}$

RESUMO: Este artigo reflete sobre posturas que o crítico e teórico Philippe Lejeune adota em suas primeiras obras, L'autobiographie en France e Le pacte autobiographique, notadamente em sua relação com um de seus objetos de estudo: as Confissões de Rousseau. Busco perceber sua postura de identidade com o objeto literário e de que maneiras essa identidade é rompida, ao mesmo tempo em que aproximo as posturas de Lejeune a reflexões de caráter teórico sobre o trabalho crítico. Tanto o movimento de identificação como o de ruptura, necessários para essa atividade, serão aqui abordados pela figuração do leitor.

PALAVRAS-CHAVE: autobiografia; Philippe Lejeune; Jean-Jacques Rousseau

ABSTRACT: This article reflects on some critical attitudes adopted by the critic and theorist Philippe Lejeune in his early works, L'autobiographie en France and Le pacte autobiographique, especially in relation to one of his objects of study: the Confessions of Rousseau. I seek to perceive how the critic first identifies himself with the literary object and then distances himself from it. At the same time I try to relate Lejeune's critical attitudes to some of the theoretical reflections on his critical work. Both processes of identification and of critical distance will be studied here through the figuration of the reader.

KEYWORDS: autobiography; Philippe Lejeune; Jean-Jacques Rousseau

\section{Dar o primeiro passo}

Lejeune afirma, no final de seu ensaio “O pacto autobiográfico” (1975):

esse estudo me parece ser antes um documento a ser estudado (tentativa de um leitor do século 20 para racionalizar e explicar seus critérios de leitura) do que um "texto científico": documento a ser adicionado ao arquivo de uma ciência histórica dos modos de comunicação literária. (LEJEUNE, 2008, p. 46)².

Respondendo ao convite que Lejeune faz ao se oferecer como objeto de estudo, reiterado em diversos momentos, dispus-me a estudar o "empreendimento impossível” de sua autocrítica. Leio os textos de Lejeune sobre autobiografia, acompanhando o movimento de revisão constante de suas formulações e a crescente presença do sujeito que reflete sobre si a fim de melhor se aproximar de seu objeto. Percebo, já nos primeiros momentos da leitura, que o objeto que construí determina o modo de abordá-lo, por conta do caráter fundamentalmente autorreflexivo do empreendimento autobiográfico - empreendimento que não se limita à autobiografia literária, mas também marca a atividade crítica.

Ao longo da obra de Lejeune, o gênero autobiográfico, tema de estudo, torna-se o ponto de vista que a obra assume — o que era a princípio uma questão de conteúdo toma a forma de transmissão. $\mathrm{O} e u$, objeto de análise das autobiografias, passa a ser o sujeito do texto crítico. Isso pode ser percebido mesmo nos títulos de suas publicações: de L'autobiographie en France, Lire Leiris e Le pacte autobiographique,

\footnotetext{
${ }^{1}$ Mestranda do programa de Estudos Linguísticos, Literários e Tradutológicos em Francês da FFLCH-USP. Membro do grupo Criação e Crítica. Contato: anameliacoelho@gmail.com .

2 "Au bout du compte, cette étude m'apparaîtrait donc être elle-même plutôt un document à étudier — (tentative d'un lecteur du XXe siècle pour rationaliser et expliciter ses critères de lecture) qu'un texte "scientifique": document à verser au dossier d'une science historique des modes de communication littéraire” (LEJEUNE, 1975, p. 45-46).
} 
que apontam a objetos de estudos ou ações do crítico, passamos a títulos que reivindicam a presença do eu: Je est un autre e Moi aussi (LEJEUNE, 2005). Analogamente, o texto redigido como estudo de outros textos abre-se para que se torne ele também objeto de reflexão. A autobiografia seria o modo de falar da autobiografia.

É numa perspectiva especular que se lançam minhas primeiras questões a respeito de caminhos a serem tomados em minha pesquisa: por quais meios o objeto determina seu modo de abordagem? Que ponto de vista tomar na leitura? Como me posicionar frente às próprias revisões que Lejeune faz de seu texto, sem necessariamente desconstruir nem simplesmente corroborar suas afirmações? De uma maneira mais ampla: qual o lugar do sujeito na crítica e na pesquisa na academia?

\section{Consciência e espelho}

\subsection{Olhar um novo objeto}

Assim comecei a dar os primeiros passos em torno do pacto autobiográfico: elegendo um ponto de partida para o trabalho, o convite aberto nos textos de Lejeune; procurando em meu projeto pontos problemáticos, rejeitando caminhos que já pareciam estéreis, escolhendo um ponto de vista a partir do qual continuar. Tal movimento prospectivo apoia-se na observação concreta, na leitura e na releitura, mas também na construção de expectativas, de traços que buscam se consolidar no futuro.

Quanto a escolha de um ponto de vista, a crítica temática mostrou-se instigante como abordagem para acompanhar minha leitura, por conta de uma série de afinidades entre seus críticos e seus objetos de estudo com a obra de Lejeune, e também em relação ao meu modo de conceber e prever minha atividade. Dentre os autores da chamada crítica temática (ou "nova crítica"), recorrerei aqui principalmente a Georges Poulet, Jean Starobinski e Marcel Raymond.

Poulet reúne, em sua análise sobre a crítica literária, um certo número de autores que compartilham preocupações e visões de mundo; principalmente, consideram em seus trabalhos a leitura como ato que se realiza na conjunção das consciências de autor e leitor:

$\mathrm{O}$ ato de ler (ao qual se reduz todo verdadeiro pensamento crítico) implica a coincidência de duas consciências: a de um leitor e a de um autor.

Ora, a conjunção dessas duas consciências é precisamente o que caracteriza, melhor do que qualquer outra, a crítica de nosso tempo. Fala-se frequentemente dela. Atribui-se a ela, em alguns meios, uma função que, até então, em nenhuma outra época, nem na de Boileau, nem na de Sainte-Beuve, nem na de Brunetière, ela não havia cumprido, senão brevemente ou de maneira fortuita. Chama-se "nova crítica", como chama-se um certo tipo de romance $o$ novo romance ${ }^{3}$.

\footnotetext{
${ }^{3}$ Todas as traduções minhas, salvo quando houver referência. "L'acte de lire (auquel se ramène toute vraie pensée critique) implique la coïncidence de deux consciences: celle d'un lecteur et celle d'un auteur. Or la conjonction de ces deux consciences est précisément ce qui caractérise mieux qu'aucune autre la critique de notre temps. On parle souvent d'elle. On lui attribue dans certains milieux une fonction que, jusqu'alors, à aucune époque, ni à celle de Boileau, ni à celle de Sainte-Beuve, ni à celle de Brunetière, elle n'avait encore remplie, sinon brièvement
} 
Por mais que a "nova crítica" seja um grupo de formação heteróclita, Poulet reforça que "a homogeneidade do grupo depende de uma preocupação comum a respeito dos fenômenos da consciência"4. Os dois grandes precursores desse modo de abordar a literatura, Mme de Staël e Charles Baudelaire, procuravam assumir “a identidade interior” dos objetos de análise, manifestando-lhes simpatia e tornando-se semelhantes a eles.

Percorrendo as ideias de críticos, numa linha do tempo que vai de Staël a Barthes, Poulet percebe, seja em positivo ou em negativo, que a experiência literária e a atividade crítica são tomadas de consciência de algo que une os seres e os fazem semelhantes. Ela é a busca de uma transparência de percorre as consciências, mas ao mesmo tempo deve dar conta da distância que as separa.

Assemelhando-se, de certa maneira, à reunião de autores de orientação diversa que Poulet promove em sua Conscience critique (1971), o diálogo crítico deste trabalho privilegia uma rede de associações entre textos que demonstram preocupações semelhantes, principalmente porque tratam da postura do autor frente a seu texto (seja o escritor e a criação, seja o crítico e seu trabalho). E ainda porque demonstram a consciência, em seus próprios textos e nos textos que são seus objetos, a marca de um pacto - consciência e pacto que busco em minha própria pesquisa.

Seja sob a forma de uma preocupação em torno da transparência, da relação, da consciência, do engajamento ou do caráter criativo da crítica literária, fios comuns percorrem os textos de Starobinski, Poulet, Raymond, Barthes e Lejeune - tanto o fruto de diálogos travados, de leituras mútuas produzidas num mesmo espaço de tempo, como o resultado de minha leitura pessoal. Cada um, à sua maneira, carrega "a justificativa de sua vinda ao mundo", dando voz à "natureza específica de um desejo, de um poder (de um gênio), que procurou alcançar-se a si próprio e a atestar-se dando nascimento à obra" 5 .

Uma mesma sedução percorreria os textos de Lejeune, movidos pelo seu desejo crítico em torno da autobiografia, e lançada adiante, em forma de convite, essa sedução encontraria sentido na minha leitura:

Esses signos me seduziram, eles são portadores do sentido que se realizou em mim: longe de recusar a sedução, longe de esquecer a revelação primeira do sentido, eu procuro compreendê-los e "tematizá-los” para minha própria maneira de pensar, e só posso fazê-lo com alguma chance de êxito à condição de ligar estreitamente o sentido ao seu substrato verbal, a sedução à sua base formal ${ }^{6}$.

ou fortuitement. On l'appelle "nouvelle critique", comme on appelle un certain type de nouveau roman le nouveau roman” (POULET, 1971, p. 9).

4 "l'homogénéité du groupe dépend d'une préoccupation commune à l'égard des phénomènes de la conscience" (POULET, 1971, p. 9).

5 "la nature spécifique d'un désir, d'un pouvoir (d'un génie), qui a cherché à s'atteindre lui-même et à s'attester en donnant naissance à l'œuvre" (STAROBINSKI, 1970, p. 24).

6 “Ces signes m'ont séduit, ils sont porteurs du sens qui s'est réalisé en moi : loin de récuser la séduction, loin d'oublier la révélation première du sens, je cherche à les comprendre à les “thématiser” pour ma propre pensée, et je ne puis le faire avec quelque chance de réussite qu'à la condition de lier étroitement le sens à son substrat verbal, la séduction à sa base formelle" (STAROBINSKI, 1970, p. 17). 
Parti então da ideia de que a crítica temática procede por uma leitura que percorre todos os níveis de um texto (das estruturas formais aos efeitos de sentido construídos no leitor), motivada por uma simpatia e centrada num tema. Projetei esse impulso nos textos de Lejeune, percebendo que a aproximação não se dá com algo presente no texto em si, mas por meio de minha leitura. Nesse primeiro movimento, tinha como princípio arranjar um jogo de espelhos. Procurava, nos reflexos de espelhos colocados frente a frente, leitor e texto crítico, uma certa identificação: a mesma que seria necessária para aceitar a transparência que o pacto demanda no texto do outro e para, em meu turno, promover essa transparência em meu próprio texto.

\subsection{Olhares sobre um mesmo objeto}

Um ponto de aproximação entre os textos críticos de minha leitura é um objeto literário comum: as obras de Jean-Jacques Rousseau, em particular As confissões, texto autobiográfico inaugural em língua francesa. Para Gagnebin e Raymond, organizadores da edição dos escritos autobiográficos de Rousseau na coleção Pléiade, sua obra deu as bases para uma "tradição autobiográfica" em língua francesa, em suas três formas principais: as memórias, o diário e o romance autobiográfico, e mesmo aos poemas em prosa de Baudelaire e à reflexão filosófica ligada à vida pessoal. De forma geral, Rousseau contribuiu para a transformação do conceito de literatura, "centrado, a partir de então, não mais na obra, ser ou objeto que existe por si só, mais no autor, e menos no autor que no homem com seu drama pessoal e sua figura insubstituível"7.

E, em consequência, Rousseau teria inaugurado não somente uma forma de produção literária, mas dado bases para a abordagem crítica da qual os temáticos se veem como herdeiros. Ao tratar da atividade de Mme de Staël em torno da obra de Rousseau, Poulet observa uma nova forma de fazer crítica:

Uma nova forma de ler se distingue aqui. O julgamento externo sobre uma obra objetiva é substituído pela participação ao movimento puramente subjetivo que essa obra revela e comunica; mas essa participação não é dissipação na obra, ela é um recomeço da obra fora dela. Algo suplementar aparece, alguma coisa que, sem a intervenção do crítico, não teria sido percebido, e só é percebido porque à distância o crítico produz um eco. Mme de Staël é talvez o primeiro crítico que teve essa grande e nova ideia da literatura, que ela tem por fim revelar o homem interior, e que revelá-lo é fazê-lo reaparecer na consciência propriamente crítica com os traços próprios que são os seus na profundidade de seu passado ${ }^{8}$.

\footnotetext{
7 “centré désormais, non plus sur l'œuvre, être ou objet existant pour soi, mais sur l'auteur, et moins sur l'auteur que sur l'homme avec son drame personnel et sa figure irremplaçable" (GAGNEBIN; RAYMOND, 1959, p. XIV$\mathrm{XV})$.

8 "Une nouvelle façon de lire se distingue ici. Le jugement externe sur une ouvre objective est remplacé par la participation au mouvement purement subjectif que cette œuvre révèle et communique; mais cette participation n'est pas un engloutissement dans l'œuvre, elle est un recommencement de celle-ci hors de celle-ci. Quelque chose de supplémentaire apparaît, quelque chose qui, sans l'intervention du critique, n'aurait peut-être pas été perçu, et qui n'est perçu que parce qu'à distance le critique y fait écho. Mme de Staël est peut-être le premier critique qui ait eu cette idée grande et neuve de la littérature, qu'elle a pour fin de révéler l'homme intérieur, et que le révéler, c'est le faire reparaître dans la conscience proprement critique avec les traits mêmes qui sont les siens dans la profondeur de son passé" (POULET, 1971, p. 23).
} 
Poulet identifica em Mme de Staël traços da postura que os temáticos desenvolvem em seus trabalhos, muitos deles sobre a obra de Rousseau. Essa "nova crítica" manifesta-se menos como fruto de um trabalho evolutivo, de diálogo ou rompimento com uma dada tradição (como pode sugerir o adjetivo que a caracteriza), do que como uma postura frente ao texto literário, de adesão e identificação à pessoa e ao passado que se exprimem na escrita e na leitura. Ela se diferencia de outras abordagens que lhe são contemporâneas, que se pretendem "impressionistas", ou que privilegiam a biografia do autor, mas apartada do sujeito crítico, ou que se concentram nas estruturas internas da obra. Segundo Starobinski, cabe ao crítico "adotar os meios conformes às exigências próprias de cada obra, e, em vez de impor a toda a literatura a mesma abordagem, nós deixaremos, por assim dizer, cada poema ou cada livro nos indicar as melhores vias de acesso", tem conhecimento (pelo contrário, usando-as a seu favor).

Logo, a postura crítica não é dada de antemão, mas construída na relação com o objeto e como consciência dessa relação. Se "Rousseau aproxima-se de si com o desejo de se compreender, e de deixar sua conduta explícita" ${ }^{\prime 10}$, ele coloca em jogo as preocupações presentes dos temáticos. Estudá-lo, acompanhando o texto em seus meandros, permite não só o esclarecimento da consciência do escritor que se lê, mas conduz o crítico a refletir sobre seu próprio trabalho de escrita, no qual se percebe, nas palavras de Starobinski, "o elo necessário entre a interpretação do objeto e a interpretação de si, entre o discurso sobre os textos e o próprio fundamento de nosso discurso" ${ }^{11}$.

Nas Confissões, para Raymond, "Rousseau foi mais longe na tomada de consciência das condições indispensáveis da autobiografia"12. De maneira análoga, para Lejeune, "não há dúvida alguma a respeito da data de nascimento precisa da autobiografia na França, e mesmo na Europa: é o ano de 1782 com a publicação das Confissões de Rousseau" ${ }^{\prime 3}$. O crítico vê nas Confissões não somente o relato de lembranças pessoais, mas a construção, em sua forma, de um pacto de verdade nesse relato e ao mesmo tempo a sua problematização, dualidade que se estende a qualquer outro empreendimento autobiográfico que lhe sucede.

O pacto, ato textual definidor do gênero autobiográfico, é a preocupação de Lejeune que move a escrita de Le pacte autobiographique (1975). Nessa "nova tentativa de definição", as ideias apresentadas anteriormente em L'Autobiographie en France (1971) foram retrabalhadas, por meio de definições e esquemas de classificação, colocando o pacto autobiográfico no primeiro plano de sua discussão teórica.

\footnotetext{
9 "adopter les moyens conformes aux exigences propres de chaque œuvre, et, au lieu d'imposer à toute la littérature la même approche, nous laisserons pour ainsi dire chaque poème ou chaque livre nous indiquer les meilleures voies d'accès" (STAROBINSKI, 1970, p. 31).

10 "il arrive à Rousseau de s'approcher de soi avec le désir de se comprendre, et de rendre sa conduite explicite" (RAYMOND, 1962, p. 210).

11 "le lien nécessaire entre l'interprétation de l'objet et l'interprétation de soi, — entre le discours sur les textes et le fondement même de notre discours" (STAROBINSKI, 1970, p. 82).

12 "Rousseau est allé plus loin dans la prise de conscience des conditions indispensables de l'autobiographie" (RAYMOND, 1962, p. 196).

13 "il n'y a aucun doute sur la date précise de la naissance de l'autobiographie en France, et même en Europe : c'est l'année 1782 avec la publication des six premiers livres des Confessions de Rousseau” (LEJEUNE, 1998, p. 26).
} 
Ainda assim, justamente no movimento de delimitação mais apurada de seu objeto, Lejeune põe em marcha uma reformulação constante de suas definições, que prosseguirá em outros textos. A crítica de Lejeune percorre uma via dupla: ao mesmo tempo que busca delimitar as fronteiras de seu objeto, abrese para a impossibilidade de seu ato. Tal perspectiva dupla é também a de Rousseau em suas Confissões, na leitura de Lejeune: a verdade da confissão na autobiografia é impossível, e porque é impossível que se tenta.

A perspectiva do espelho me pareceu, inicialmente, um modo produtivo para tratar do meu objeto, ao observar, nos primeiros momentos de minha pesquisa, que o texto de Lejeune se move pelo reflexo do objeto (a autobiografia) no sujeito. O pacto, tema de sua preocupação teórica mais evidente, toma parte em seu texto e de sua postura como crítico - não somente ele vai analisar o pacto, mas assumi-lo. Isso se daria porque nas autobiografias que são seu objeto, Lejeune constata que o pacto é menos uma questão de conteúdo do que de forma: o autobiógrafo deve promover em seu relato um ato de engajamento em torno do que é relatado. Prestando-se a identificar por que meios uma autobiografia é lida como tal, Lejeune leu e construiu seu texto com os mesmos instrumentos que recolheu em sua leitura. Os mesmos mecanismos atuantes em seu objeto de estudo moveriam então seu próprio texto crítico.

\subsection{Olhar outro objeto}

Ao analisar Rousseau, Lejeune afirma que tentou "não dizer nada que o próprio Rousseau não tenha dito. Se não adotei sua linguagem, ao menos a sua problemática e seu ponto de vista” ${ }^{14}$, ele estaria colocando em funcionamento as ideias de Poulet, para quem as obras dependem da consciência de quem as lê, mas ela é uma consciência conjunta de si e do mundo. Num movimento de confluência, o dever primordial do crítico seria retomar o Cogito inicial do escritor: "o ato crítico exigia da parte daquele que o colocava, a mesma atividade interna que o ato de consciência do autor criticado. Um mesmo EU devia operar no autor e no crítico" ${ }^{15}$.

Ora, tendo em vista que o gênero autobiográfico é algo que se refaz continuamente, a crítica de Lejeune, para que dê conta de seu objeto, não deve se assentar na estabilidade; será por princípio incompleta, parcial. Também oscilante e autorreflexiva, a mim caberia prolongar esse desejo, colocá-lo em movimento por meio de minha leitura.

No entanto, talvez a imagem de meu pacto, objetivada e prefigurada, não se fixasse num espelho. Algo em sua limpidez me pareceu suspeita, questões turvaram a paisagem na qual eu procurava encontrar o meu texto. Escolhi então outra imagem que me obseda, a fratura, como antecipação dos passos por vir em minhas leituras e como problema que move a crítica e a minha escrita.

\footnotetext{
14 "ne rien dire d'autre que ce que Rousseau dit lui-même. J'ai adopté sinon son langage, du moins sa problématique et son point de vue” (LEJEUNE, 1975, p. 77).

15 "l'acte critique exigeait de la part de celui qui le posait, la même activité interne que l'acte de conscience chez l'auteur critiqué. Un même JE devait opérer chez l'auteur et chez le critique” (POULET, 1971, p. 311).
} 
O que explica minha mudança de lente da câmera que uso para captar meu objeto? Estaria eu, ao criar imagens-expectativas, percebendo que o reflexo entre os textos não é pleno, dando conta das três restrições às quais a crítica deve obedecer, segundo Barthes?

A crítica duplica os sentidos, faz flutuar acima da primeira linguagem da obra uma segunda linguagem, isto é, uma coerência de signos. Trata-se em suma de uma espécie de anamorfose, ficando bem entendido que por um lado a obra não se presta nunca a um puro reflexo (não é um objeto especular como uma maçã ou uma caixa) e por outro lado que a própria anamorfose é uma transformação vigiada, submetida a constrangimentos ópticos: daquilo que ela reflete, ela deve transformar tudo; só transformar segundo certas leis; transformar sempre no mesmo sentido. São esses os três constrangimentos da crítica (BARTHES, 1970, p. 221)

Como conciliar o desejo suscitado pela leitura e a natureza fugidia do objeto no rigor que se impõe ao trabalho crítico? Talvez o trabalho crítico se faz menos num movimento de enlace do que de embate. Cabe ao sujeito, leitor, cúmplice e crítico, afinar a consciência de seu lugar no jogo, exercício constante. Tal consciência é também levantada por Lejeune em seu trabalho:

Para obter algum rigor, somos levados a falar em termos gerais e absolutos de um fenômeno que, sabemos bem, é historicamente muito limitado; e a fundamentar a existência de um corpus de obras cuja constituição se deu na maior confusão. Não seríamos capazes de fugir dessa contradição entre o método de definição, e a natureza do objeto a definir: o melhor a fazer é manter-se consciente. ${ }^{17}$

De toda forma, sob o espelho ou sob a fratura, à percepção de um problema na disposição das peças do jogo segue-se um novo lance que busca o rearranjo, que prolonga o movimento. Levo em meu texto a interrogação sobre o que move os críticos de minhas leituras a falar de coisas próximas, levando meu texto em direção ao que me move a continuar suas palavras.

\section{Leitura e fratura}

\subsection{Ler um novo objeto}

Em seu convite, Lejeune sugere que seu texto é um exercício de leitura, mais do que um "texto científico", no qual o objeto seria tratado de maneira isolada de seu contexto, supomos, dissecado numa essência intemporal. Perceptível não somente como resultado do trabalho com os textos (e como

\footnotetext{
16 "Le critique dédouble les sens, il fait flotter au-dessus du premier langage de l'œuvre un second langage, c'est-àdire une cohérence de signes. Il s'agit en somme d'une sorte d'anamorphose, étant bien entendu, d'une part que l'œuvre ne se prête jamais à un pur reflet (ce n'est pas un objet spéculaire comme une pomme ou une boîte), et d'autre part que l'anamorphose elle-même est une transformation surveillée, soumises à des contraintes optiques : de ce qu'elle réfléchit, elle doit tout transformer; ne transformer que suivant certaines lois; transformer toujours dans le même sens. Ce sont là les trois contraintes de la critique" (BARTHES, 1966, p. 64).

17 "Pour obtenir quelque rigueur, on est amené à parler en termes généraux et absolus d'un phénomène dont on sait bien qu'il est historiquement très limité ; et à fonder en raison l'existence d'un corpus d'œuvres dont la constitution a eu lieu dans la plus grande confusion. On ne saurait échapper à cette contradiction entre la méthode de définition, et la nature de l'objet à définir : le mieux qu'on puisse faire est d'en rester conscient" (LEJEUNE, 1998, p. 9).
} 
encaminhamento de leitura que ele mesmo dá ao que escreveu), a posição de leitor que Lejeune assume é o que permite a existência do texto crítico:

Partindo da situação de leitor (que é a minha, a única que conheço bem), tenho a possibilidade de captar mais claramente o funcionamento dos textos (suas diferenças de funcionamento), já que foram escritos para nós, leitores, e é nossa leitura que os faz funcionar. É, portanto, através de uma série de oposições entre os diferentes textos que foram submetidos à leitura que tentei definir a autobiografia (LEJEUNE, 2008, p. 14$)^{18}$.

Está na leitura o ponto de partida de Lejeune para a própria existência da autobiografia. Desde sua primeira tentativa de definição global da autobiografia em língua francesa, a mudança dos modos de leitura é parâmetro-chave para o surgimento do gênero. Por mais que memorialistas tenham empreendido relatar a história de suas próprias personalidades, durante a Idade Média ou a Renascença, a sociedade europeia não dispunha naquele momento de um sistema literário que desse conta da noção de autor individual. As distinções que se operam hoje entre biografia e autobiografia não funcionavam até a metade do século XVIII, época em que começam a circular textos ficcionais em forma de memórias, que, segundo ele, dão espaço para a circulação de textos autobiográficos (LEJEUNE, 1998, p. 42-43).

Lejeune se coloca, por conseguinte, como leitor historicamente situado: "um leitor contemporâneo que tenta achar uma ordem em uma massa de textos publicados, cujo tema comum é contar a vida de alguém" (2008, p. 13)19, capaz de identificar uma autobiografia ao perceber a identificação paratextual de um mesmo nome que se desdobra nas instâncias de autor, narrador e personagem:

O que define a autobiografia para quem a lê é, antes de tudo, um contrato de identidade que é selado pelo nome próprio. E isso é verdadeiro também para quem escreve o texto. Se eu escrever a história de minha vida sem dizer meu nome, como meu leitor saberá que sou eu? (2008, p. 33)

Os procedimentos narrativos da ficção e do relato autobiográfico se assemelham, se copiam, transitam entre um gênero e outro. Numa análise estritamente interna, não haveria diferença entre uma autobiografia e um romance autobiográfico. O gênero autobiográfico participa de um fenômeno mais amplo, num sistema baseado em convenções sociais, como o estado civil, na cadeia da produção editorial, organizada em torno da escrita, publicação e leitura: "é nesse nível global que se define a autobiografia: é tanto um modo de leitura quanto um tipo de escrita, é um efeito contratual historicamente variável" (LEJEUNE, 2008, p. 46). Esse acordo no qual todas as instâncias de produção e recepção do texto devem se inserir funciona porque se compartilha um dado repertório de regras e convenções, vinculadas ao ato de leitura.

\footnotetext{
18 "En partant de la situation de lecteur (qui est la mienne, la seule que je connaisse bien), j'ai chance de saisir plus clairement le fonctionnement des textes (leurs différences de fonctionnement), puisqu'ils ont été écrits pour nous, lecteurs, et qu'en les lisant, c'est nous qui nous les faisons fonctionner. C'est donc par des séries d'oppositions entre les différents textes qui sont proposés à la lecture, que j'ai essayé de définir l'autobiographie" (LEJEUNE, 1975, p. 14).

19 "un lecteur d'aujourd'hui qui cherche à distinguer un ordre dans une masse de textes publiés, dont le sujet commun est qu'ils racontent la vie de quelqu'un” (LEJEUNE, 1975, p. 13).
} 


\subsection{Leituras de um mesmo objeto}

É como "leitura" que dois dos primeiros livros de Lejeune se apresentam ao leitor. Lire Leiris é uma experiência de leitura das autobiografias de Leiris, escrita em seu desenrolar: "uma transformação do leitor pelo seu trabalho sobre a linguagem, passando do jogo da interpretação à prática da escritura"20. "Leitura" é o título dado à segunda parte do volume Le pacte autobiographique, na qual se encontram os textos de análise das autobiografias de Rousseau, Gide, Sartre e Leiris; nesse conjunto de cinco textos, dois são dedicados à leitura das Confissões, em particular do Livro I. É justamente considerando a obra crítica como fruto de leituras compartilhadas que Lejeune destaca a sua leitura das Confissões de Rousseau:

Como é construído o livro I das Confissões? Apoiando-se nas indicações dadas pelo próprio Rousseau, Jean Starobinski, Marcel Raymond e Michel Launay já tentaram responder a essa questão: veremos o quanto eu lhes sou devedor ${ }^{21}$.

Contudo, ao mesmo tempo em que sua leitura de Rousseau é também a leitura de outros textos críticos, Lejeune demonstra o quanto a sua se pretende singular. Isso porque Lejeune não cala o que outros críticos se recusaram a ler — é o caso de toda a análise do episódio das palmadas, segundo ele central para a leitura do conjunto da obra de Rousseau (1975, p. 49-52), que ele encontra silenciado nos críticos com quem dialoga. Sua leitura se distingue das demais porque, caminhando pelos desvios, seguindo linha a linha o episódio, Lejeune toma direções diferentes das já abertas por outras leituras, no intento de encontrar novas paisagens.

Sem ignorar os discursos críticos que cercam seu objeto, ele toma o que foi descartado por outras leituras para encontrar a sua própria — que será a mais próxima da consciência de seu objeto, o que ele demonstra no próprio texto: "eu tentarei mostrar que é pela leitura dos desvios que a ideologia de Rousseau se esclarece" ${ }^{22}$. E essa leitura dos desvios dá conta menos do conteúdo da confissão (e com isso são descartadas as leituras psicanalíticas do comportamento masoquista de Rousseau, por exemplo) do que da conduta confessional, da forma como a confissão é feita.

Lejeune não empreende uma leitura contra o texto; pelo contrário, considera que o texto solicita o leitor. Em sua própria construção, abre espaço para que a leitura se transforme e que o leitor transforme o texto - porque percebe que seu objeto já lhe possibilitou tal abertura: "a técnica narrativa [de Rousseau] transforma a confissão em romance policial, o leitor estando requisitado para participar do deciframento, e estimulado pelo anúncio de descobertas interessantes"23.

\footnotetext{
20 "une transformation du lecteur par son travail sur le langage, passant du jeu de l'interprétation à la pratique de l'écriture" (LEJEUNE, 2004).

21 "Comment le livre I des Confessions est-il construit ? En s'appuyant sur les indications données par Rousseau luimême, Jean Starobinski, Marcel Raymond et Michel Launay ont déjà essayé de répondre à cette question : on verra combien je leur suis redevable" (LEJEUNE, 1975, p. 87).

22 “j'essaierai de montrer que c'est par la lecture des écarts que l'idéologie de Rousseau s'éclaire” (LEJEUNE, 1975, p. 88).

23 "la technique narrative [de Rousseau] transforme l'aveu en roman policier, le lecteur étant requis de participer au déchiffrement, et stimulé par l'annonce de découvertes intéressantes..." (LEJEUNE, 1975, p. 63).
} 
Ao responder ao apelo concreto do texto de Rousseau, Lejeune o tira do silêncio e da recusa crítica, fazendo-o funcionar como ato de escrita, ao mesmo tempo em que se coloca, leitor, igualmente em ato. Em sua crítica, Lejeune parece narrar o movimento do texto de Rousseau, que só toma existência — como autobiografia — enquanto leitura.

Se um autor não escreve para si mesmo, o outro, ao ler o texto, lhe dá existência. Entre a espera do leitor e o convite do texto, sujeito e objeto se formam num movimento de busca. Não só o texto ganha sua forma na leitura, mas em sentido inverso o leitor se constitui como sujeito pela leitura, dois agentes distintos num esforço conjunto. A leitura é uma experiência existencial de formação do sujeito — leitor, escritor, crítico — meio de identificação entre as instâncias que participam do texto. O crítico, primeiramente despertado como leitor, percebe que em sua experiência de leitura encontra-se também a experiência do escritor: porque escrever é reiterar um ato que começou na leitura. Ao tratar do episódio das palmadas de Mlle Lambercier, Lejeune identifica uma mesma demanda de amor, que percorre tanto o personagem Rousseau, como o narrador-autor, que dirige ao leitor sua confissão como uma declaração de amorosa:

A ignorância e a inocência da criança, e as do leitor, coincidem aqui. O narrador desvela lentamente as coisas, arremedando o caminho da tomada de consciência da criança. Através de todos esses meandros, uma única coisa permanece fixa e fundamental: o amor. Eis o que era necessário nos fazer sentir ${ }^{24}$.

O que Lejeune faz, então, é atender ao chamado de Rousseau, caminhando ao longo do percurso de tomada de consciência da criança, tomando-a para si e lançando-a adiante, num ato em que o amor pelo outro supera o amor-próprio — ou em que o amor-próprio se reveste da necessidade do olhar e da resposta do outro? A tomada de consciência da criança não se faz pela vivência por si só, mas pelo modo como ela é escrita, transmitida. A preocupação da empreitada autobiográfica não é atender a uma referência externa ao texto, mas colocar a forma da busca da consciência de si em primeiro plano, plano esse que tenta fazer-se reverberar em todos os outros. A autobiografia se faz em sua forma de composição, mais do que pelo conteúdo que transmite.

Raymond observa em sua leitura do livro I das Confissões que, para o jovem Rousseau leitor dos romances herdados de sua mãe, "a consciência de si é, em seu texto, consciência de leitor e de leitor de romances"25. A consciência romanesca de Rousseau, escritor de romances, que busca na escrita de suas confissões o conhecimento de si, incide na consciência do crítico Raymond. Sua consciência crítica, movida pela leitura de Rousseau, não tende a objetivar as circunstâncias da escrita, listar os conteúdos de que vai tratar; em outro caminho, busca, pela escolha de certos pontos de vista particulares, numa forma construída por uma leitura particular, uma explicação de si mesmo:

estes estudos pertencem ao que poderíamos denominar uma crítica geral, que eles não são nem exaustivos nem objetivos. "A objetividade" não teria sentido numa pesquisa desse gênero, na qual engaja-se necessariamente a si mesmo, pela escolha de

\footnotetext{
${ }^{24}$ "L'ignorance et l'innocence de l'enfant, et celles du lecteur, coïncident ici. Le narrateur dévoile lentement les choses, mimant le cheminement de la prise de conscience de l'enfant. À travers tous ces méandres, une seule chose reste fixe et fondamentale : l'amour. C'est ce qu'il fallait nous faire sentir" (LEJEUNE, 1975, p. 57).

25 "la conscience de soi est chez lui conscience de liseur et de liseur de romans" (RAYMOND, 1962, p. 96).
} 
pontos de ótica, de exemplos, pela maneira com que se lê, acentuando ou não tal qualificativo ou uma inflexão, o autor que se tenta explicar-se a si mesmo ${ }^{26}$.

Lejeune alarga a leitura de Raymond ao afirmar que "o livro I conta como se passa da leitura à escritura, ou seja, como se tornar escritor"27. O livro I, microcosmo de todas as Confissões, contém a experiência central de Rousseau - leitor, escritor e crítico; ou, se nos ativermos à obra, na formação de Rousseau personagem, narrador e autor. Dizer "Rousseau" é operar na tripla identidade que funda a autobiografia, é por meio de um mesmo nome percorrer três instâncias apartadas no tempo e no espaço, mas que buscam se conjugar na transparência da palavra escrita.

A leitura é uma experiência original e total: "não somente a experiência da leitura é primeira, mas ela apresentada como originária (é de lá que vem a sequência) e total (toda a sequência)”28.

Como, para o Rousseau autobiógrafo, "o que se vê é somente uma parte mínima do que é” ${ }^{29}$, a experiência com o texto escrito do personagem Rousseau criança, lida como busca para uma ausência, é uma e mesma experiência e falta primeira, a inexistência da mãe, que reverbera em todos as dimensões do texto: no interior do primeiro livro; na divisão de seus episódios; na relação do primeiro livro com o último; nas Confissões e na obra de Rousseau como um todo. No fio do primeiro livro, a leitura dos romances é tanto o ponto inicial da consciência de si, como o ponto final, ao qual deve convergir a existência:

O herói da autobiografia vê sua consciência emergir da leitura (p. 8), depois se absorve na leitura (p. 40-41). A leitura, ou seja a relação com o texto escrito, não figura no relato como uma lembrança anedótica, mas como experiência original e constitutiva, e como termo. [...] A mãe é um romance. E todo romance será um retorno à mãe, único signo que permanece dela. [...] O que o narrador produz nas duas pontas do livro, como lembrança e como sonho, é, em realidade, a própria leitura de seu herói ${ }^{30}$.

Haveria então, na transparência da escrita, o retorno à origem, de onde o sujeito emergiu e na qual ele se dissolverá, em nome da identificação? Nesse mesmo sentido, a leitura de Lejeune aspira à identificação com seu objeto?

\footnotetext{
26 “ces études relèvent de ce qu'on pourrait nommer une critique générale, qu'elles ne sont ni exhaustives ni objectives. "L'objectivité" n'aurait pas de sens dans une recherche de ce genre, où l'on s'engage nécessairement soimême, quand ce ne serait que par le choix des points d'optique, des exemples, par la manière dont on lit, en accentuant ou non telle épithète ou une inflexion, l'auteur qu'on essaye de s'expliquer à soi-même" (RAYMOND, 1962, p. 11).

27 "le livre I raconte comme on passe de la lecture à l'écriture, c'est-à-dire comment on devient écrivain" (LEJEUNE, 1975, p. 93).

28 “non seulement l'expérience de la lecture est première, mais elle est présentée comme originaire (c'est de là que vient la suite) et totale (toute la suite)" (LEJEUNE, 1975, p. 105).

29 “Ce qui se voit n'est que la moindre partie de ce qui est” (ROUSSEAU, 1959, p. 1149).

30 "Le héros de l'autobiographie voit sa conscience émerger de la lecture (p. 8), puis se résorber dans la lecture (p. 40-41). La lecture, c'est-à-dire le rapport au texte écrit, ne figure pas dans le récit comme souvenir anecdotique, mais comme expérience originelle et constitutive, et comme aboutissement. [...] La mère est un roman. Et tout roman sera retour à la mère, seul signe qui reste d'elle. [...] Ce que le narrateur produit aux deux bouts du livre, comme souvenir et comme rêve, c'est, en réalité, la lecture même de son héros" (LEJEUNE, 1975, p. 92).
} 


\subsection{Ler outro objeto}

Nessa perspectiva, o trabalho crítico se resumiria então à leitura, que se desdobra de um texto a outro, que se abre infinitamente a outras leituras? Indo mais longe, o crítico pode se investir do papel de leitor-médio, guiando a leitura dos não-críticos, servindo de parâmetro para o funcionamento dos textos, para a sua circulação e compreensão?

Barthes busca um lugar para a atividade de crítica literária, entre a ciência da literatura e a leitura. As três atividades ocupariam lugares distintos, mas serviriam a uma mesma busca pela verdade. Da leitura à crítica, o que muda é a relação do sujeito com a escrita:

Ler é desejar a obra, é querer ser a obra, é recusar duplicar a obra fora de qualquer
outra palavra que não seja a própria fala da obra: o único comentário que poderia
produzir um puro leitor, e que continuaria sendo tal, é o pasticho (como o indicaria o
exemplo de Proust, amador de leituras e de pastichos). Passar da leitura à crítica é
mudar de desejo, é desejar não mais a obra mas a sua própria imagem. Mas por isso
mesmo, é devolver a obra ao desejo da escritura, do qual ela saíra (BARTHES, 1970,
p. $230-231)^{31}$.

Por um lado, a crítica de Lejeune se faz ler como a atividade de um leitor, e nela manifesta o desejo múltiplo dos leitores em torno da coisa escrita, como objeto de desejo e como preenchimento a uma falta inicial, multiplicando experiências de leitura e procurando fazer continuar esse desejo. Contudo, o fato de passar pela escrita transforma essa pura atividade de leitura — em que poderia haver identificação, absorção de sujeito e objeto — numa atividade fraturada. Logo, Lejeune não é tãosomente um leitor, pois:

o crítico não pode, de modo algum, substituir o leitor. [...] mesmo que se defina o crítico como um leitor que escreve, isto quer dizer que esse leitor encontra em seu caminho um temível mediador: a escritura.

Ora, escrever é de certa forma fraturar o mundo (o livro) e refazê-lo (BARTHES, 1970 , p. 228-229) ${ }^{32}$.

A crítica literária, nesse sentido, assume o risco de dar um sentido particular à obra, um sentido dentre vários que são compartilhados pelos leitores. Deve ir além do puro reflexo da obra, fazendo-se "um saber sobre a linguagem retomado numa nova linguagem; uma análise do evento poético elevada por sua vez à condição de evento"33. Ainda assim, entendo que uma crítica da autobiografia, assim como a autobiografia, deve mostrar as dificuldades da empreitada, aos olhos do leitor, a quem caberá julgar o destino.

\footnotetext{
31 “Lire, c'est désirer l'œuvre, c'est vouloir être l'œuvre, c'est refuser de doubler l'œuvre en dehors de toute autre parole que la parole même de l'œuvre : le seul commentaire que pourrait produire un pur lecteur, et qui le resterait, c'est le pastiche (comme l'indiquerait l'exemple de Proust, amateur de lectures et de pastiches). Passer de la lecture à la critique, c'est changer de désir, c'est désirer non plus l'œuvre, mais son propre langage. Mais par là-même aussi, c'est renvoyer l'œuvre au désir de l'écriture, dont elle était sortie” (BARTHES, 1966, p. 79).

32 "le critique ne peut en rien se substituer au lecteur. [...] même si l'on définit le critique comme un lecteur qui écrit, cela veut dire que ce lecteur rencontre sur son chemin un médiateur redoutable : l'écriture.

Or écrire, c'est d'une certaine façon fracturer le monde (le livre) et le refaire” (BARTHES, 1966, p. 77).

33 "un savoir sur la parole repris dans une nouvelle parole; une analyse de l'événement poétique promue à son tour au rang d'événement" (STAROBINSKI, 1970, p. 33).
} 
Podemos então admitir que escrever é engajar-se, manifestar-se em meio à batalha, à arena, frente aos olhos dos outros, sob observação atenta, oferecer-se como objeto de julgamento. Isso porque, de maneira mais ampla, a escrita, profunda e imediata, particular e comum, é movida pela consciência da realidade humana, da nossa presença diversa no mundo. Mas que engajamento é esse, que inevitavelmente nos leva ao seu próprio rompimento?

As questões que me coloquei no início deste texto - que ponto de vista tomar em meu texto, qual o meu lugar frente aos textos que são meu objeto de leitura e estudo? - dependem justamente de uma reflexão sobre o pacto e que formas esse engajamento toma na atividade crítica.

O engajamento da escrita é tanto diferente do desejo que se opera na leitura, como diferente do engajamento do indivíduo com o mundo. A escrita funciona sob regras próprias, que ela mesma fornece. É por si um engajamento pela diferença e singularidade de seu ato, que não termina em si, mas pressente um perigo, pressupõe uma perda, e não existe sem ela e não pode aniquilar essa incompletude. Sua existência depende dessa falta primeira, falta constitutiva da sua existência.

\section{Contar a história}

Buscando fazer parte do mesmo jogo de inversão da linguagem que Lejeune lê em Rousseau e que Lejeune traz para o seu texto, em vez de procurar entender de que maneiras um texto está terminado, quero saber em que bases começarei um novo. E ainda, em vez de passar a olhar com olhos de outro um texto meu, quero me reconhecer eu num texto de outro.

Entre reconhecer-se num texto de outro e construir um novo texto, procurei distinguir dois movimentos: começa-se pela fabricação de um espelho, pelo desejo de identificação; terminada a construção do espelho, a identificação se rompe; a ela deve se seguir a sua fratura.

Por mais que estudar a autobiografia demande o engajamento e a consciência de um pacto, de um acordo entre instâncias que se separam no tempo e no espaço, mas que se conjugam no ato de leitura, não é possível manter a identificação entre sujeito e objeto até o fim — mas somente partir desse desejo. O objeto parece uno quando eu o vislumbro, mas me aproximar dele é perceber a fratura que nos contém, e promover novas e sucessivas fraturas.

A fratura não invalida a construção do espelho. Tanto um momento como outro são necessários à escrita, atividade em que se manifesta um certo tipo de recaída: a reincidência de um ato que se percebe pela leitura, ato de linguagem que nos funda enquanto indivíduos, cuja origem não podemos encontrar, mas somente prolongar.

Contudo, a fratura que eu pretendia operar em meu objeto, etapa de um plano a que me submeti, antecipa-se a mim mesma. Meu próprio objeto já estava construído sobre uma fratura, confirmando o que, só depois de constatá-la, encontrei formulado por Barthes: "o signo é uma fratura que não se abre jamais senão sobre o rosto de um outro signo"34.

\footnotetext{
34 "le signe est une fracture qui ne s'ouvre jamais que sur le visage d'un autre signe"(BARTHES, 2007, p. 72).
} 
As fraturas que se sobrepõem seriam o reflexo dessa falta primeira que move o desejo em torno do escrito, construído e desconstruído na atividade essencialmente dúbia, binária, da linguagem. Nesse sentido, a identificação se dá mais na fratura, do que na transparência do espelho. Em vez de ruptura, distanciamento, a fratura é signo compartilhado, que nos reúne em torno dos atos de leitura, escrita - e crítica: espelho disforme, construído por pedaços em constante rearranjo. O efeito de se mirar nesse espelho pode ser a bigarrure, a junção de cores que contrastam, forma heteróclita que Rousseau previa para suas Confissões, forma essa já prefigurada por Montaigne em seus Ensaios... - a maneira de contar a própria história.

E seria possível que meu texto conte sua própria história? Onde se encontra a minha leitura, se irreconhecível e dispersa num conjunto de fraturas? O sujeito que escreve, movido por um pacto, deve ter consciência da abertura de seu texto, do espaço que cabe ao leitor, respondendo à questão "quem é ele?", que leitor move o texto, a quem ele se dirige. E em que medida o leitor pode ser eu mesma tornar-me leitora do meu próprio texto para tentar apreender o modus operandi que nele se efetivou, a despeito de minhas intenções e previsões.

O que percebo é que, mesmo a expectativa que moveu minha leitura-escrita, que me levou a percorrer caminhos já traçados, dentre os quais pude vislumbrar o meu, ela se esquiva de mim mesma e me surpreende. Mesmo eu tendo procurado a fratura, colocando-me sob uma regra, prefigurando meu percurso, a escrita não está sob o controle senão de si própria — quebrando o espelho mas deixando ainda, em seus pedaços, reflexos aquilatados.

Espelho fraturado, que levanto à minha frente mas no qual espero que o leitor se veja. 


\section{Referências bibliográficas}

BARTHES, Roland. Crítica e verdade. São Paulo: Perspectiva, 1970.

. Critique et vérité. Paris: Seuil, 1966.

. O império dos signos. São Paulo: Martins Fontes, 2007.

GAGNEBIN, Bernard ; RAYMOND, Marcel. "Introduction aux Confessions". In: ROUSSEAU, JeanJacques. Euvres complètes I. Paris: Gallimard, 1959.

LEJEUNE, Philippe. "De l'autobiographie au journal, de l'Université à l'association :

itinéraires d'une recherche”. Conférence à l'Université Ain Chams (Le Caire), 28 mars 2005. Disponível em: <http://www.autopacte.org/Itin\%E9raires_d\%27une_recherche.html>. Acesso em: 11 jan. 2010.

. L'autobiographie en France. 2. ed. Paris: Armand Colin, 1998.

Le pacte autobiographique. Paris: Seuil, 1975.

. Lire Leiris: Autobiographie et langage. 2004. Disponível em:

<http://www.autopacte.org/Lire-Leiris-intro.html>. Acesso em: 11 jan. 2010.

. O pacto autobiográfico : de Rousseau à Internet. Belo Horizonte: UFMG, 2008.

POULET, Georges. La conscience critique. Paris: José Corti, 1971.

RAYMOND, Marcel. Jean-Jacques Rousseau : la quête de soi et la rêverie. Paris: José Corti, 1962.

ROUSSEAU, Jean-Jacques. Euvres complètes I. Paris: Gallimard, 1959.

STAROBINSKI, Jean. La relation critique: L'oeil vivant II. Paris: Gallimard, 1970.

Artigo recebido em: 09/03/2010

Artigo aprovado em: 09/03/2010

Referência eletrônica: COELHO, Ana Amelia. Espelho, fratura: notas sobre a crítica de Philippe Lejeune, Revista Criação \& Crítica, n. 4, p. 182-196, 2010. Disponível em:

<http://www.fflch.usp.br/dlm/criacaoecritica/dmdocuments/15CC_N4_ACoelho.pdf> 